\title{
Developing a Continuity of Operations Plan
}

The prospect of a pandemic outbreak of H1N1 influ-

Lenza in 2009 prompted the Dean of the Z. Smith Reynolds Library to charge the Disaster Preparedness Committee with developing a detailed business continuity plan. The Committee had already in past years developed concise plans for potential personal safety, water and fire-related crises. The Z. Smith Reynolds Library is the undergraduate library for Wake Forest University in WinstonSalem, NC. Wake Forest University has an undergraduate enrollment of approximately 4500 and the Z. Smith Reynolds Library holds approximately 1.7 million volumes. The Z. Smith Reynolds Library has a well-developed Disaster Plan (http://zsr.wfu.edu/about/publications/). This plan was hammered out over several years by members of the Library Disaster Preparedness Committee. The Disaster Plan covers emergency procedures for various problems such as water or

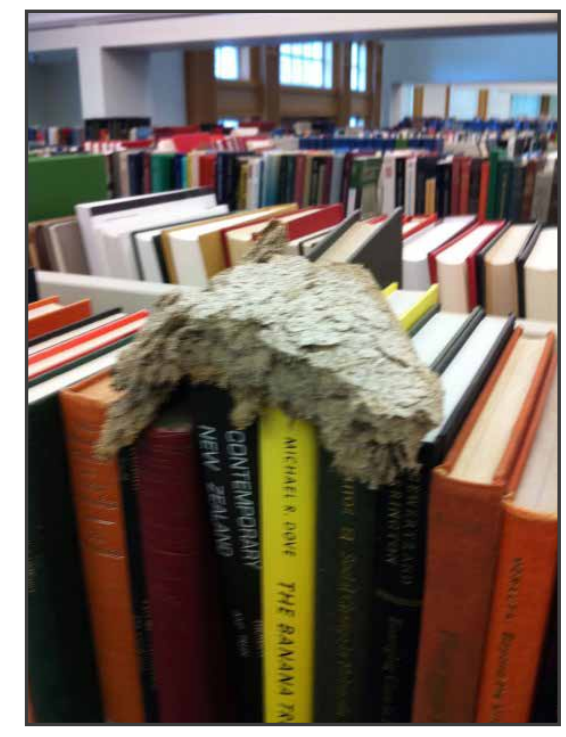

fire-relate events, hurricanes and bomb threats. This Disaster Plan has been fine-tuned after each actual event in the library. The committee has responded to numerous disasters in and outside our library. These are primarily water-related problems such as sewage or pipe leaks.

In 1995, following a thunderstorm, the committee cut its teeth on a water disaster that resulted from a faulty pipe connection. Ironically, a smaller leak occurred shortly before the major one. For this event, we fanned the pages of the books on site (unfortunately, these same books got wet again in a few weeks when

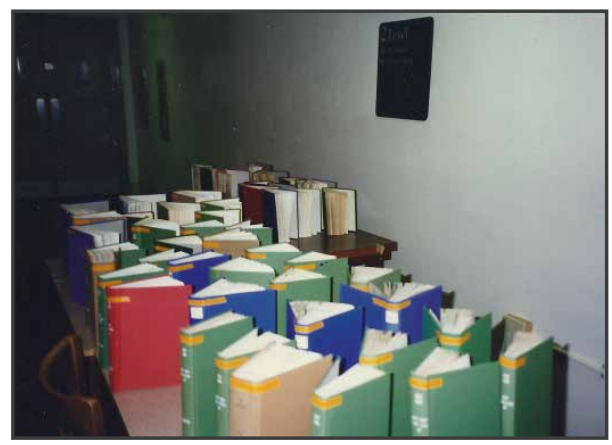

a poorly repaired pipe fitting failed).

This pipe was mounted over a dropped ceiling, and resulted in water damage to an entire floor. All of the damaged materials were boxed and stored in a freezer until they could be freeze dried. Hundreds of boxes of frozen books were shipped from [name of city and state] to El Paso, Texas for freeze drying. During this time, the library evaluated the usefulness of these damaged materials and were able to weed some titles. Other damaged titles were discarded, but replaced by our sister institution who did not need them. Upon their return, the damaged books were quickly processed and returned to the shelves. A second disaster struck our library in 2003, when a water main broke in our remote storage facility. This event was unusual because it was not actually in our library building, but at our off-site storage facility. The severity of the water damage was minimal. As a group we decided to return as many of the titles as possible to remote storage. Slightly damp materials were air-dried by fanning the pages of the books and leaving them for about a week. Damp materials were frozen. Six months later, we determined the frozen materials could also be successfully air-dried, which we did. Some of these materials were slightly warped and cockled and were placed into book presses for several weeks.

Our committee is also responsible for evacuation during fire drills and an annual library safety briefing for staff. During fire drills, the committee helps clear the library and evacuate patrons and staff to safe locations. The committee also ensures no one enters the building until the all clear is given by University Police and Fire units. We have conducted fire extinguisher training with the fire department for interested library staff. This was a popular training activity and helped take the mystery off the fire extinguishers hanging on our walls. The Disaster Committee has also conducted training at intervals for library staff. This training usually involved the packaging of wet books using special boxes and stacking techniques. 


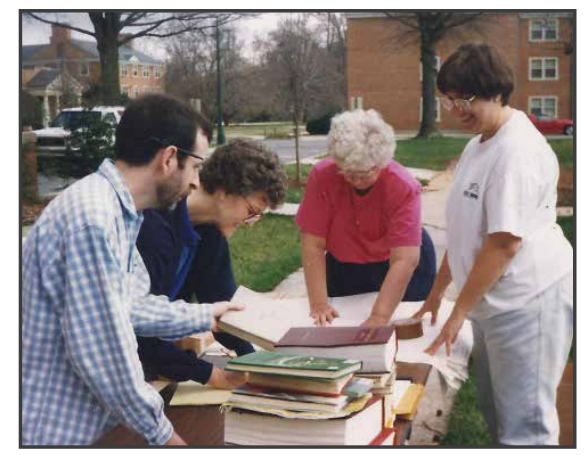

In addition, four library staff members have gone through the week-long CERT (Community Emergency Response Team) training. CERT training involves first aid, hazardous chemicals, disaster response and fire suppression.

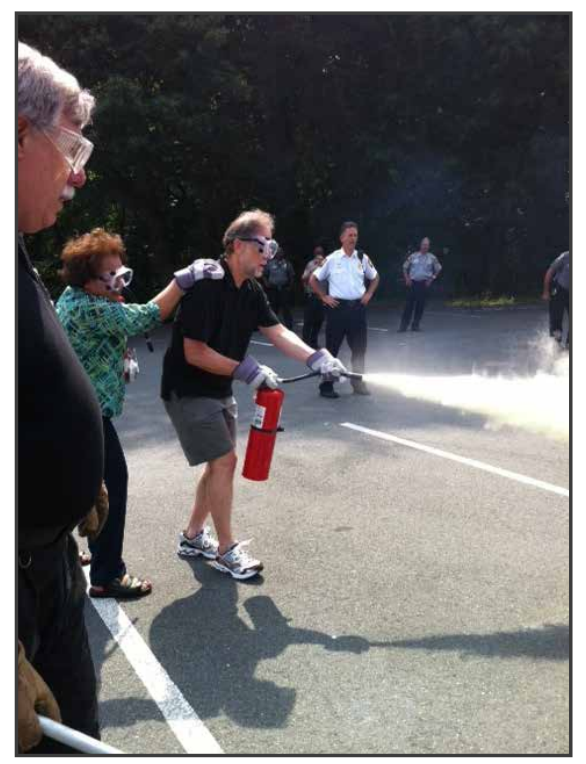

For the past few years, our Library Disaster Preparedness Committee has struggled to create a new stand-alone plan in response to the latest swine flu (H1N1) outbreak. The swine flu outbreak had been characterized by some individuals at the time (20092010) as a pandemic or as a strong pandemic possibility. This made our library contemplate a variety of situations where our existing Disaster Plan would be insufficient. How would we, for instance, deliver services if our patrons could not actually set foot on campus for some reason, such as a quarantine. To address this insufficiency, the Disaster Preparedness Committee embarked on the creation of a Continuity of Operations Plan (COOP). Our new COOP Plan would attempt to address situations, possibly caused by a pandemic or other disastrous event. In this situation, the library would be forced to deliver library services from off-campus or to our students abroad.

The first attempts at a COOP Plan were simply lists of who would do this or that. Although the lists were relatively complete, these initial efforts did not quite do the trick. The university had made an effort to create a COOP Plan during the bird flu scare, but did not include the library in its plan formulation. Why, the library was left out is not clear but it may have been a plan that focused more on emergency responses where people are affected, not our library materials or continuing our service operations. The Virginia Tech tragedy brought another layer of preparation to developing a plan that included personal safety elements. The Disaster Committee did finally realize that we could not create a COOP Plan alone, and would need the input from each library team. What a realization! Realizing that we needed input from each team helped the committee plot our course forward.

The Disaster Preparedness Committee next searched online for a COOP Plan we could adapt to the Z. Smith Reynolds Library. We found the plan we could adapt and use as a template at University of North Carolina at Chapel Hill Department of Environment, Health and Safety (http://ehs.unc.edu/healthy/coop. shtml). This plan was thorough, and we asked for and received permission to use and adapt the UNC COOP
Plan. The Disaster Preparedness Committee initially met and went through each section of the template together and essentially re-wrote it to custom-fit our institution. The template we used was sent to each library team. We asked each team to list each internal and external dependency, phone contacts, chain of command and key procedures. Each library team spent a good deal of time developing their portion of the COOP template. This work by each team was almost an abstract operation where they planned for incidents that they knew may never happen. It forced each group to think imaginatively about how they could function, even in a reduced form, if our library was experiencing reduced capabilities due to a disaster. Each team in our library has a unique mission, so these individual team submissions to the COOP Plan were all different. The Access Services Team's contribution to the COOP Plan was much different that the Special Collections contribution because each of these teams has a different responsibility to patrons and the library. Some of the library teams experienced real difficulties designing their portion of the plan while trying to answer hard questions: how would individual information be updated (people are always moving in and out of jobs); would the technology be available for say, Inter-Library Loan; would individuals have access to their university laptop computer if they were at home; and how would a phone tree actually work if one link was, for some unforeseen reason lost? When each team had completed their section of the template, our committee compiled this information into one plan. This plan was then edited and streamlined into a consistent document. 
The Continuity of Operations Plan is composed of these sections:

- Departments Objectives: what the key function of each department consists of;

- Emergency Communications systems: how we communicate via phone and email;

- Team's Essential Function: this is a list of each function a team is responsible for and a primary and alternate contact;

- Department's Leadership Succession: a prioritized list of responsible people with their contact information;

- Emergency Access to Information and Systems: maintenance of key documents, computers and work flow;

- Key Internal Dependencies: a listing of departments on campus with important reliances;

- Key External Dependencies: listing of vendors and suppliers which are key to the function of each team;

- Feasible Workflow Strategies: a discussion by each individual team about how they would function in various scenarios, such as having the university campus quarantined;

- Recovery after an Event: managing operations with limited resources or personnel

By getting input from each team, our committee was able to put together a document that included unique information from each team. Each team had thought about and listed contingencies and which personnel would be available for their array of library services. This COOP Plan is now as comprehensive at it could be and allows for the innerworkings and individuality's of each library team. This plan does not just address the disruption of library services during a flu pandemic. It sets up a scheme whereby our library could carry on some operations for our patrons, even if those operations are very limited. Each team has a predeveloped game plan for carrying on any operations they can in a disaster or other event preventing them from their normal duties. This COOP plan has now entered a netherworld where we hope we never have to use it, but have it available in an emergency. This plan also needs continual stewardship efforts because responsible people are constantly moving to new jobs or retiring which leaves a hole in the plan. It is a continuing challenge for the Z. Smith Reynolds Library Disaster Committee to keep a plan we have never used current. Additionally, it has been very difficult for each team to plan for an unseen and unknown event.

\section{Resources Consulted}

As the Disaster Preparedness Committee embarked on this project, a review of the professional library literature and searches of library-related and professional websites disclosed a dearth of library-specific planning resources pertinent to the possibility of a new pandemic. The few articles relevant to maintaining library functions and services during a global outbreak originated, not unexpectedly, during earlier pandemic alarms, notably the avian flu of 2006, although there also were numerous sites and articles that provided influenza information resources for library patrons, of a public service nature.

The following review of resources, ranging from library associations and professional literature, to government publications and websites, includes material the committee located and utilized in order to develop a COOP plan for the library, as well as more recent material.

\section{Literature Review}

Case studies predominate in the pandemic planning literature and when focused on library planning, the library is generally positioned, legitimately, in the context of institution-wide concerns. A 2007 article by Lisa McGuire, "Planning for a Pandemic Influenza Outbreak: Roles for Librarian Liaisons in Emergency Delivery of Educational Programs,"1 details the search for resources that would meet needs associated not just with library services but with the educational mission of a university. Noting the relentless emergence of influenza outbreaks during the past 300 years, McGuire outlined the scenarios presented to library liaisons affiliated with the School of Public Health at the University of Minnesota Twin Cities campus. Scenarios ranged from projections of a brief interruption measured in weeks if a pandemic were to strike in the middle of a semester, to more extended institutional closure in the range of nine to eighteen months. Social distancing characterized the basic strategy as did a presumption that telephone and computer infrastructures would remain functional (McGuire, 4). The initial assumption was that librarians' contributions in such scenarios would consist of applying reference skills to provide a literature review of other institutions' approaches to pandemic planning, as well as tutorials, pathfinders, and FAQs that would address students' research needs. Digital reference services such as IM and chat also came under consideration. However, it became clear that larger issues had to be addressed, revolving around the resources and instruction needed to enable students to complete interrupted academic courses. The final report of the task force reflected needs for expertise in e-learning systems. 
Recommendations addressed continuation of academic courses by means of email, Blackboard, pre-recorded lectures, and live audio. Long-term efforts to implement electronic tools were emphasized and included developing incentives to motivate faculty to adopt more technology. The undertaking demonstrated that librarians can play a significant role in developing an action plan and a range of options to permit coursework to continue despite the social distancing necessary for containing the spread of pandemic infection.

The 2006 avian flu provided the impetus for an overview of essential principles for continuity planning at the University of Alberta. "Preventing Pandemonium: Pandemic Preparedness Planning and Communicable Disease Outbreak Management in a University Setting" recounts how a Public Health Response Committee commissioned by senior university administrators carried out its mandate to develop a nexus of business continuity, human resources and communications plans, as well as a decision-making model. Notably, the strategy was to be grounded in ethical decision-making principles that would inform the protection of the university community, transparency, accountability, fairness, and safeguarding of individual rights. The public health response strategy consisted of three stages of action corresponding to the World Health Organization Pandemic Phases, i.e."pre-pandemic, pandemic alert, pandemic period, and post pandemic/recovery" (Grundy, et al., 18-19). Central to the strategy was the mandate for all departments to "complete a detailed planning tool that will enable them to identify critical services, functions, personnel and backups; consider options to continue to deliver critical services in the event of disruption; work in partnership with other departments, faculties or external partners regarding planning for shared critical services; and identify inventory requirements such as equipment needs to deliver critical services" (Grundy, et al., 19-20). Planning for emergency communication was also stipulated, as was a recovery phase of restoring normal operations and evaluating the response. An actual outbreak of norovirus in a residence center resulted in an unanticipated case study in managing a communicable illness outbreak on the campus, testing systems and processes in the university's plan. Subsequent debriefing indicated the need for further training on crisis communications and the development of comprehensive department-specific business continuity plans.

The prospect of pandemic disease in 2005 garnered attention in The Chronicle of Higher Education. In an article title that would still resonate several years later, "Flu Plan: Colleges Struggle with How They Would React to a Pandemic," Lila Guterman projects a scenario of virulent disease spreading through unprepared ivory towers. However, she notes that most colleges are not in the position of having to commence at square one; many have emergency plans in place initiated after earlier events such as the anthrax attacks of 2001 or SARS in 2003, when, for instance, The University of North Carolina at Chapel Hill had to deal with a SARS diagnosis in a staff member. A survey of seventeen institutions by The Chronicle revealed that all monitor information from the Centers for Disease Control and Prevention and remain in contact with public health agencies, have response committees in place, and provide information for faculty, staff, and students. Detailed plans have been prepared by the some institutions. For example, the University of Minnesota Emergency Operations $\operatorname{Plan}^{4}$ specifies that all departments essential to the University's continued operation establish formal continuity plans, to include identification of critical processes, identification of alternative worksites, backup of essential data and equipment, and procedures for recovering affected operations and responsibilities, including assisting other departments.

\section{Professional Association Literature}

Resources pertaining to pandemic planning have appeared in recent years as published guidelines and white papers by professional associations for higher education and health.

Over the course of the previous decade, the American College Health Association has issued a series of guidelines, addressing various aspects of potential pandemics as the threats emerged. In 2003, its VaccinePreventable Diseases Task Force issued "Guidelines for Preparing the University for SARS."5 Although dealing with an earlier threat of global epidemic, the document provides a succinct overview of hazards posed in a university setting, noting the potential for rapid disease transmission due to the number of faculty, students, and other individuals who may travel to and from SARS-affected locations. The outline of pre-event planning includes both internal and external alert mechanisms and university preparation working groups drawn from various academic units (omitting libraries, however). Special attention is paid to students' academic and financial concerns due to protracted class absence, and to emergency communication modes: mass email, website announcements, 
telephone systems, as well as written, spokesperson, and media relations communications.

In July of 2006, the American College Health Association prepared "Guidelines for Pandemic Planning." 6 The publication provides summary information, specifying a potential absenteeism rate of four to twelve percent of the workforce that could be sick at any time and absent from work for anywhere from one to fourteen days, impacting all levels of human resources. Institutional closing time is projected to be eight to twelve weeks. As recourse, the plan recommends "depth charting" (p. 2) for positions of leadership, cross training, and teleconnectivity so that work may be carried out from home. After defining non-pharmaceutical interventions (social distancing, isolation, quarantine, protective sequestration, and public health education), the guidelines address business continuity issues that may lack the imperative of health and safety concerns but nonetheless must be attended to. The "Getting Started" section outlines key steps in developing a pandemic response plan, which could be adapted from an existing emergency plan. These steps include identification of key members of a pandemic planning group, essential functions and personnel, appropriate communication channels, the chain of command at various levels of functioning (including an "incident commander" who would bear primary responsibility for coordinating the response), and the role of the student health service. The guidelines also recognize the inevitability of ethical dilemmas, and recommend consultation with legal counsel regarding ethical and legal issues, particularly for highly charged concerns surrounding human resource management, safety, and resource rationing (p. 5). A separate section is devoted to action triggers for implementing plans, emphasizing that critical decision making must be carried out in a curtailed time frame. Additional resources cited include websites, pandemic supply lists, pandemic planning committee suggested members, FAQs and sample communication drafts.

In September 2009, the next in the series of ACHA Guidelines addresses another specific pandemic threat, "Campus Response to Novel Influenza H1N1." Noting the historical arc of pandemic planning, frequently based on the scenario of the 1918 virus which also disproportionately affected young people, the document opens by citing mitigation strategies: campus evacuation and cancellation of academic and social activities for eight to twelve weeks (none of which were deemed necessary at that point in time). Much of the document focuses on community education and isolation and care of the ill. For the former, a library can clearly serve as an information portal, utilizing national and public health organizations' resources. Isolation of sick students is a "significant challenge" on a university campus, and the document emphasizes the importance of communicating guidelines to students and reassuring them of flexibility in dealing with their academic concerns. The document concludes by addressing human resources issues, noting that both sick employees should be encouraged to remain home by offering flexible schedules and paid time off for their periods of illness. For students, stress and anxiety are exacerbated by missing classes, falling behind with their academic work, and losing various support mechanisms. Arguably, continuity of library services constitutes a significant mode of support in addressing these significant academic concerns.

\section{Government Sources}

\section{FEMA}

The Federal Emergency Management Agency/FEMA, part of the U.S. Department of Homeland Security, offers a series interrelated documents for pandemic planning, ${ }^{8}$ including detailed planning templates (with sample text) prepared by the National Continuity Programs, to guide continuity planning by non-federal as well as federal organizations. The "Pandemic Influenza Continuity Annex Template" contains supplemental elements for entities that already have continuity plans in place, but need to incorporate pandemicrelated considerations. The template covers operations (including risk management, budgeting, and COOP implementation phases); pandemic planning assumptions (a twenty percent illness rate among working adults, but a forty percent absenteeism rate due to illness, caregiving, and fear of infection, with a six to eight week outbreak span of time for each wave of pandemic); identification of essential functions; orders of succession and delegations of authority "at least three deep per position" to take into account absenteeism rates; continuity facilities and communications that can function without person-toperson contact; testing, training, and exercise programs; transfer of control to pre-determined parties; and finally, resumption of normal operations. The threat to human resources is starkly described as "the primary threat to maintaining essential functions and services during a pandemic outbreak" (p. 8), necessitating absence from the workplace for prolonged periods of time while physical infrastructure remains intact. The core strategy for protecting human resources and their families, emphasized throughout the template, is 
implementation of practices such as social distancing, hygiene, control of infection, and employee crosstraining. A "meta checklist," entitled "Key Elements of Departmental Pandemic Influenza Operational Plans," and a "Continuity of Operations for Pandemic Influenza” brochure essentially reiterate in more succinct form these essential elements and considerations for developing a viable continuity plan.

\section{Centers for Disease Control}

The Centers for Disease Control and Prevention issued "CDC Guidance for Responses to Influenza for Institutions of Higher Education during the 2009-2010 Academic Year" in August 2009. ' The document, currently archived but still accessible, provides broad guidelines directed both at minimizing the number of people who might succumb to influenza and reducing educational and social disruptions. Recommendations range from administrative-level policy issues to housekeeping and basic hygiene practices, and include suggested policy revisions for student absenteeism as well as sick leave policies for faculty and staff, which might otherwise make it difficult for individuals to remain at home when ill or when faced with a need to care for affected family members. Self-isolation from classes or social events evolves, in more severe scenarios, to class suspension and distance learning, possible short-term student withdrawal, and modified work responsibilities and locations of faculty and staff. The document concludes with a list of questions to prompt decision-makers to identify and to communicate objectives, policies and courses of action.

The current website, Flu.gov, maintains a page for "Pandemic Awareness," 10 covering the broad topics "About Pandemics" (characteristics and challenges), "Current Situation" (in the U.S. and internationally), and "Global Activities" (multiple links for monitoring pandemic flu, monitoring $\mathrm{H} 5 \mathrm{~N} 1$ avian flu, and pandemic planning activities). This last section contains links to several WHO/World Health Organization documents and publications on pandemic preparedness, planning, and response.

Another page on Flu.gov deals with School Planning, addressing pandemic as well as seasonal flu in various documents directed at schools K-12 or colleges and universities. The "Colleges and Universities Pandemic Influenza Planning Checklist" includes sections on Planning and Coordination, Continuity of Student Learning and Operations, Infection Control Policies and Procedures, and Communications Planning. Among the recommendations are the following, relevant to library planning: accountability and responsibility designations; scenarios for varying degrees of illness in the campus community and corresponding containment measures (cancelling classes and campus events, closing campus and housing); consistency with university, community, and state plans; alternate and redundant modes of emergency communications (including social media); plan testing; and a recovery plan that addresses the pandemic consequences in terms of staff and student losses, as well as operational and financial effects. The continuity of student learning and operations checklist comprises two issues: developing alternative means to provide continuity of instruction in case the university closes, and developing a continuity of operations plan for carrying out the institution's core functions. Infection control policies singles out hygiene practices and supplies, as well as the importance of establishing sick leave policies specific to pandemic flu, a "non-punitive, liberal leave" that ensures that those with pandemic influenza leave campus and return only when recovered from all symptoms.

Finally, "Preparing for the Flu (Including 2009 H1N1 Flu): A Communication Toolkit for Institutions of Higher Education," from the CDC, was designed to assist in implementing the CDC's recommendations listed in its "Guidance for Responses to Influenza for Institutions of Higher Education during the 2009-2010 Academic Year." The toolkit includes questions and answers based on the 2009-2010 Guidance publication; fact sheets with "action steps" for limiting influenza contagion; and templates for posters, emails, letters and announcements pertaining to flu conditions and university class status. Reiterated throughout all of these CDC publications is the need to balance risk of illness for a vulnerable demographic group with benefits of keeping students in class; to implement liberal sick leave policies during severe flu conditions (recognizing that absence from work for seven days or more may be necessary in order to mitigate the spread of the pandemic influenza); and to devise ways of working or studying from home.

\section{Library \\ Association Resources}

The American Library Association online store and the Association of College and Research Libraries publications catalog offer multiple books on disaster response, including Miriam B. Kahn's Disaster Response and Planning for Libraries ${ }^{11}$ (now in its third edition and available also as an e-book), and ACRL's recent 
Comprehensive Guide to Emergency and Disaster Preparedness and Recovery. ${ }^{12}$ Neither of these focuses on pandemic planning, but each contains pertinent recommendations regardless of disaster type. Although the Kahn volume addresses physical disasters, such as fire, water damage, and tornadoes, the book includes relevant factors to consider in its sections on planning for disaster response (communication, responsibilities, priorities, service providers), coping with mental and emotional stress, and revising plans, couched in terms of enabling continuity of library business and provision of quality service.

ACRL's Comprehensive Guide to Emergency Preparedness and Disaster Recovery addresses primarily non-pandemic emergencies, but nonetheless presents relevant considerations. The authors emphasize in its first chapter that any comprehensive disaster plan must have "buy-in and support from employees from every area of the library" (p. 3), regardless of whether the impetus for developing a plan comes from a library director or from a staff librarian. In addition, support from campus officials is needed to ensure that the campuswide plan dovetails with the library's plan; integrating a library plan into existing campus plans is a key part of the process. Periodic revision is necessary, particularly for emergency contact information, both internal and external (pp. 4, 27). The extensive range of topics covered includes disaster preparedness, writing the disaster plan, training, emergency, disaster recovery, case studies, bibliography, and appendices (a model plan; companies, societies and organizations to consult; relevant professional journals; and recovery services).

The ACRL CLIP Note \#40, Emergency Response Planning in College Libraries, ${ }^{13}$ is a compilation of planning documents grouped by categories: tables of contents and summarizing outlines of organization, communication, and priorities from sample college plans; plans' disaster response steps to emergency situations; prevention strategies; internal and external resources; and recovery (insurance, reports, and resumption of business). The publication also includes disaster response survey results and a useful bibliography of resources, both print and web-based. The situations to which the plans are oriented are non-pandemic disasters, and reflect crises of recent years: Katrina, September 11, Virginia Tech. However, the recommendations embrace all types of emergencies: commence with a phased approach to planning that addresses issues of acute concern, making use of a growing array of available templates and models; and conduct a periodic review of the literature to garner new approaches to disaster preparedness (p. 3) as part of the process of continual updating of plans. References to epidemic/pandemic health emergencies occur in a few plans, for instance that of Trinity University.

The American Library Association provides an informative "Pandemic Preparedness" page of sources, ${ }^{14}$ including lists of federal, state and local government resources; professional associations and online sites; information for updating links, RSS feeds and even widgets; background information sources on influenza; and most usefully, a concise list of topics to address in a library policy, with the caveat that they should be consistent with the parent institution's plans. Topics range from broader considerations such as criteria under which the library and its programs would be closed down and policies governing sick leave and work from home, to hygiene issues, communications plans for both staff and users, and public education efforts.

\section{University Continuity of Operations Plans}

Although resources discussed above cite and reiterate numerous points that would merit consideration and incorporation into a continuity plan, the library's Disaster Preparedness Committee members wished to find a template with a clearly delineated structure and a significant degree of specificity, which would provide a uniform approach for the various library teams and their service functions. Some of the topics discussed in the literature, such as administrative policies for sick leave and payroll or financial issues, were determined to be beyond the purview of this library committee. Universities often have emergency preparedness websites; some have pandemic plans as well. The University of Mississippi, for example, has a fourteen page Campus Pandemic Plan outline, linked as a pdf document from the University's Emergency Information/ Pandemic Information web page. ${ }^{15}$ The statement of purpose notes that the document "is not a comprehensive campus plan but one that serves as an overview with specific departments having comprehensive plans." Preliminary material includes a statement of purpose, definition of pandemic, and assumptions regarding campus consequences and availability of external resources. The outline headings include operations (mitigation via raising awareness, providing information, and response contingencies); organization and assignment of responsibilities; direction and control (by incident commander and Chancellor or designee); administration and logistics, and a tabular plan organized by broad 
university administrative units, broken out by Stage 1 (confirmed cases in the U.S.), Stage 2 (suspected cases on campus or in town), and Stage 3 (confirmed cases on campus) phases of pandemic. In the latter stage, only essential personnel would be required to actually come to work on campus. No specific mention is made of campus libraries' services and staffing exigencies.

A link on the ALA website to the Department of Environment, Health, and Safety Department at the University of North Carolina at Chapel Hill proved to be the most promising, offering a comprehensive, substantive Pandemic Influenza Emergency $\operatorname{Plan}^{16}$ that includes guidelines, templates, and FAQs for creating a plan for one's own library. The specific elements in the plan are listed as follows:

- Objectives of the Department or Unit

- Essential Functions

- Identification of Communicable Disease Emergency Mandatory Employees

- Key Internal Dependencies

- Key External Dependencies

- Emergency Access to Information \& Systems

- Emergency Communication Systems

- Leadership Succession

- Mitigation Strategies

- Recovery of Operations

The full template is enriched by extensive explanatory information, providing context, background, and specific options or examples, and it is prefaced by an explanation of the institution's planning assumptions, based on potential absenteeism rates and timeframes for possible disruptions of supplies. Departmental objectives are defined as the "unique mission" that encompasses research, teaching, and service. Emergency communication systems are to include a call tree, but additional modes of communication are listed as possible options for various contingencies: instant messaging, web site, pagers, etc. The departmental essential function template reflects the need for multiple layers of contacts for each essential function: primary, alternate, and second alternative contact persons. Similarly, departmental leadership succession charts list the head and three successors. "Key internal dependencies" refers to services or products provided by units or departments within the institution; by contrast, external dependencies are providers and suppliers outside of the institution. A mitigation strategies section calls for steps that can be taken immediately to minimize the impact of a future pandemic upon departmental operations, such as developing flexible work-from-home contingency procedures. A variety of exercises (with specific dates requested) includes options for testing a department's plans; and finally, a recovery section identifies issues to be addressed, such as resumption of normal services, inventory supplies, continued absenteeism, earned time off, and emotional needs of staff.

The plan's succinct but comprehensive and flexible outline had immediate appeal, and lent itself to the development of a modified template that the Disaster Preparedness Committee could propose to the library administration for consideration as the basic rubric for developing a continuity of operations plan, modified as needed by considerations drawn from literature and other resources such as those outlined above.

The authors would like to acknowledge the contributions of Scott Adair in researching, developing, writing, and editing the Z. Smith Reynolds
Library Continuity of Operations Plan discussed in this article.

\section{References}

${ }^{1}$ Lisa McGuire, "Planning for a Pandemic Influenza Outbreak: Roles for Librarian Liaisons in Emergency Delivery of Educational Programs," Medical Reference Services Quarterly 26 (2007): 1-13.

2 Lorie Grundy, et al., "Preventing Pandemonium: Pandemic Preparedness Planning and Communicable Disease Outbreak Management in a University Setting," Health Law Review 16 (2007): 17-24.

3 Lila Guterman, "Flu Plan: Colleges Struggle with How They Would React to a Pandemic," Chronicle of Higher Education 52 (Dec. 2005): A27-A28, accessed December 3, 2012, http://chronicle.com/article/ Facing-Down-the-Flu/35305. 4 "Operational Continuity Plan," University of Minnesota,

Department of Emergency Management. Last modified October 26, 2012, http://www1.umn.edu/prepared/emmgmt.html .

5 "Guidelines for Preparing the University for SARS," American College Health Association, last modified July 2007, http://www. uwlax.edu/police/Sars_Guidelines. pdf

6 "Guidelines for Pandemic

Planning," American College Health Association, last modified July 2006. www.acha.org.

7 "Campus Response to Novel Influenza H1N1," American College Health Association, last modified September 2009, http://www.acha. org/publications/guidelines_whitepapers.cfm.

8 "Planning \& Templates: FEMA Planning Continuity Guidance," U. S. Department of Homeland 
Security, Federal Emergency

Management Agency, last modified June 2012, http://www.fema.gov/ planning-templates\#1.

9 "CDC Guidance for Responses to Influenza for Institutions of Higher Education during the 2009-2010 Academic Year," Centers for Disease Control and Prevention, last modified February 2010, http://www.cdc. gov/h1n1flu/institutions/guidance/.

10 "Pandemic Awareness," Centers for Disease Control and Prevention, last modified 2012, http://www.flu.gov/ pandemic/index.html.
${ }^{11}$ Miriam B. Kahn, Disaster Response and Planning for Libraries, (Chicago: American Library Association, 1998).

${ }^{12}$ Frances C. Wilkinson, Linda K. Lewis, and Nancy K. Dennis, Comprehensive Guide to Emergency Preparedness and Disaster Recovery. (Chicago:

Association of College and Research Libraries, 2010).

${ }^{13}$ Marcia Thomas and Anke Voss, compilers, Emergency Response Planning in College Libraries. (Chicago: Association of College and Research Libraries, 2009).

14 "Pandemic Preparedness," American Library Association, last modified March 18, 2011, http://www.ala.org/ tools/pandemic-preparedness

15 "Pandemic Information," University of Mississippi, last accessed December 3, 2012, http://www.olemiss.edu/emergency/Pandemic.html. 16 "Pandemic Influenza Emergency Plan," University of North Carolina at Chapel Hill, Environment, Health and Safety, last modified 2009, http://ehs.unc.edu/healthy/panflu/.

\section{North Carolina Libraries}

Official Publication of the North Carolina Library Association

ISSN 0029-2540

The subscription cost to North Carolina Libraries is $\$ 50 / y r$.

All issues are available online free-of-charge at http://www.ncl.ecu.edu.

Back issues are available from the North Carolina Library Association office at 1811 Capital Blvd., Raleigh, NC 27604 , for $\$ 8$ an issue for those years prior to going online in 2002 , or $\$ 50$ for the annual print compilation beginning with Vol. 60 (2002). 